\title{
The effect of two diets on the growth, reproduction and ultimate size of guinea-pigs
}

\author{
By D. LISTER AND R. A. McCANCE \\ Medical Research Council Department of Experimental Medicine, \\ University of Cambridge
}

\section{(Received 21 December 1964-Accepted 28 fanuary 1965)}

The guinea-pig first achieved fame as an experimental animal in the eighteenth century, when Lavoisier used it for his fundamental experiments on respiration (Lavoisier \& La Place, $\mathrm{x}_{7} 84$; Seguin \& Lavoisier, 1793). It did not, however, begin to make nutritional history till the twentieth century, when Holst \& Frölich (1907), in trying to give it beriberi, found that it developed scurvy instead; they thus opened up scurvy to an experimental attack. The guinea-pig, however, has never approached the rat in popularity for general nutritional work, and this is unfortunate, in that the guinea-pig has many points of resemblance to man in its rate of growth and reproductive performance (McKeown, I960).

The traditional diet for guinea-pigs in one of the laboratories in Cambridge was based on a sugar-beet pulp mixture (see below) and had always been reckoned to give satisfactory results. It was made up of $5^{6} \mathrm{~g}$ sugar-beet pulp which was soaked and drained and to which were then added $40 \mathrm{~g}$ bran, $34 \mathrm{~g}$ oats, $\mathrm{I} \mathrm{g}$ dried yeast and $\mathrm{I} \mathrm{g}$ fish meal-or the desirable multiple of these amounts. A supplement of cod-liver oil was given weekly. When a stock of pure-bred guinea-pigs was obtained for work in our laboratory, the decision was made to rear them on a pelleted diet based on the original one described by Short \& Gammage (I959) as diet S.G I, and now marketed commercially by Joseph Rank Ltd, which was certainly easier to handle. It was also decided to compare the efficacy of the two diets for growth and reproduction; some of the results are described below.

\section{EXPERIMENTAL}

Twenty-four pure-bred guinea-pigs (Frant strain) were divided into two lots of ten females and two males and placed in two roomy pens at ground level in a warm environment. They were given plenty of straw and provided with unrestricted food and water. The design of the feeding troughs enabled a record to be kept of the amount of food taken. About I $_{5} 00 \mathrm{~g}$ cabbage were added to each pen per week; virtually all of it was consumed.

The composition of the diets provided for the two groups is given in Table $\mathrm{I}$, which shows that their calorific values were roughly the same if the carbohydrate is reckoned 'by difference'. The sugar-beet diet, however, contained considerably more fibrous carbohydrate and was thus more bulky and probably, even for a herbivore like the 
guinea-pig, less calorific per roo g than diet S.G. I. It also contained less protein and a little less fat.

Most litters were born during the night; all new litters present at 9 am were reckoned to have been born on that day. 'The birth weights, sexes and the numbers in the litter were recorded, and each newborn was given a distinctive and permanent mark with a different colour or colour combination for each litter.

Table I. Compositions of the two diets, expressed/100 g food

Moisture (g)
Ash $(\mathrm{g})$
Total $\mathrm{N}(\mathrm{g})$
Protein $(\mathrm{N} \times 6 \cdot 25)(\mathrm{g})$
Fat $(\mathrm{g})$
Sugar $(\mathrm{g}) \quad$
Starch $(\mathrm{g}) \quad$ by difference
Carbohydrate (g) : available
Calories excluding unavailable
carbohydrate (kcal)
Calories including unavailable
carbohydrate (kcal)

$\begin{array}{cr}\text { Sugar-beet diet } & \text { Diet S.G. I } \\ 12 \cdot 2 & \text { I } 1 \cdot 7 \\ 7 \cdot 0 & 7 \cdot 2 \\ 2 \cdot 0 & 3 \cdot 3 \\ 12 \cdot 2 & 20 \cdot 5 \\ 3 \cdot 4 & 5 \cdot 1 \\ 14 \cdot 1 & 6 \cdot 3 \\ 19 \cdot 4 & 27 \cdot 6 \\ 33 \cdot 5 & 33 \cdot 9 \\ 65 \cdot 2 & 55 \cdot 5 \\ 202 & 264 \\ 334 & 352\end{array}$

The young in each litter were weighed daily until they were 7 days old and subsequently weekly. At 4 weeks of age they were weaned, the males and females were separated, and each was ear-marked, the number in the left ear denoting the mother's diet, and that in the right the individual's experimental number. They were then allocated randomly to one or other of the two dietary treatments, so that animals of all birth weights and experiences up to weaning were present on both. The young were weighed weekly until they died or were killed. The whole experiment was carried out three times on the first three litters of the same mothers, and later litters were used for additional birth weights and weaning weights and for analytical studies.

The effect of the diets on the weight at birth and at maturity was studied, as also the composition of the body, based upon determinations of total body water, total body fat, weights of viscera, skin and hair, dimensions of the femur, length of body (nose to anus), length of head (nose to base of skull), and length of the small and large intestines.

\section{RESULTS}

Table 2 shows the amounts of the two diets consumed by the animals during their first pregnancy and during their first lactation. The results are approximations only, in that $(a)$ the animals did not all give birth at the same time and there were, therefore, transitional periods in which the animals were not all in the same state; $(b)$ the young began to consume some solid food soon after birth; to overcome this to some extent the figures are expressed per $\mathrm{kg}$ weight of adults and offspring taken together. In spite of these shortcomings, the figures show that during pregnancy the mothers ate more dry matter and obtained more calories on the sugar-beet diet, if the carbohydrate is reckoned by difference, but got little more if the fibrous carbohydrate is excluded 
from the calculations. They obtained roughly the same amount of protein on both diets, but the large intake of roughage on the sugar-beet diet must have reduced the amount of the protein available for maintenance or growth (McCance \& Walsham, 1948-9; Meyer, 1958). During lactation the intake of dry matter rose much less on the sugar-beet than on diet S.G. I, probably because of the bulky nature of the former (Dalton, 1965 ). Whereas, therefore, the animals still got more calories/100 $\mathrm{g}$ on the sugar-beet diet, if the carbohydrate is reckoned by difference, they got fewer calories if the fibrous carbohydrate is excluded from the calculation and much less protein.

Table 2. Daily food consumption of guinea-pigs on two diets in terms of dry matter, protein and calories, expressed per $\mathrm{kg}$ body-weight of all the animals in the pen (adult and young together)

\begin{tabular}{|c|c|c|c|c|}
\hline \multicolumn{5}{|c|}{ Total calories ( $\mathrm{kcal})$} \\
\hline Diet & $\begin{array}{l}\text { Dry matter } \\
\text { (g) }\end{array}$ & $\begin{array}{l}\text { Protein } \\
\text { (g) }\end{array}$ & $\begin{array}{c}\text { With } \\
\text { carbohydrate } \\
\text { by difference }\end{array}$ & $\begin{array}{c}\text { With } \\
\text { available } \\
\text { carbohydrate }\end{array}$ \\
\hline \multicolumn{5}{|c|}{ During pregnancy } \\
\hline $\begin{array}{l}\text { Sugar-beet } \\
\text { S.G. r }\end{array}$ & $\begin{array}{l}41 \cdot 5 \\
27 \cdot I\end{array}$ & $\begin{array}{l}5 \cdot 0 \\
5.4\end{array}$ & $\begin{array}{r}\mathbf{1} 33 \\
89\end{array}$ & $\begin{array}{l}85 \\
72\end{array}$ \\
\hline \multicolumn{5}{|c|}{ During lactation } \\
\hline $\begin{array}{l}\text { Sugar-beet } \\
\text { S.G. I }\end{array}$ & $\begin{array}{l}57 \cdot 2 \\
50 \cdot 6\end{array}$ & $\begin{array}{r}6 \cdot 8 \\
10 \cdot 1\end{array}$ & $\begin{array}{l}223 \\
167\end{array}$ & $\begin{array}{l}117 \\
134\end{array}$ \\
\hline
\end{tabular}

Table 3. Effect of two diets on the numbers in successive litters of guinea-pigs, their total weights and the weights of the individual young

(Mean values with standard deviations for I7 I live-born animals from forty-eight litters born to mothers on diet SG $x$ and 104 live-born animals from thirty-eight litters born to mothers on the sugar-beet dict)

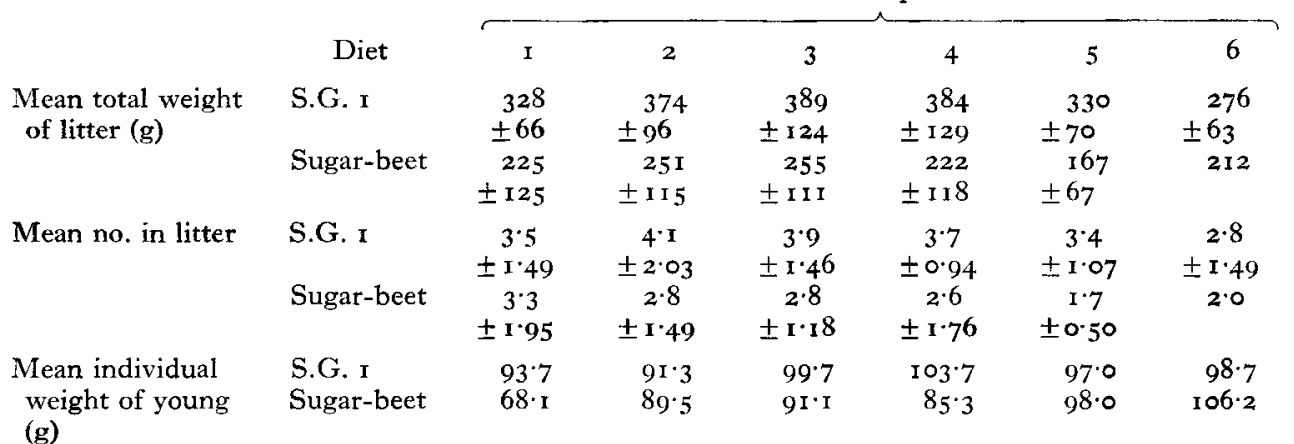

Since guinea-pigs commonly mate immediately post partum (Rowlands, I949), it was possible to calculate the total number of litters that might have been born in the time available to each mother. The results show that the mothers on diet S.G. I had $83.6 \%$ of the litters they might have had if they had all mated successfully immediately after parturition, whereas those on the sugar-beet diet had only $69.3 \%$. The records demonstrated that this difference in fertility was brought about by a fall in the number 
of successful matings immediately after parturition and not by an increase in the length of gestation.

Table 3 shows the effect of the two diets on the mean numbers in, and total weight of, six successive litters and the mean weights of the individual young in each. The total weight of the average litter on diet S.G. I was greater than that of the corresponding litter on the sugar-beet diet. The mean number in the first litter was the same on each diet, and the mean weights of the young were consequently smaller on
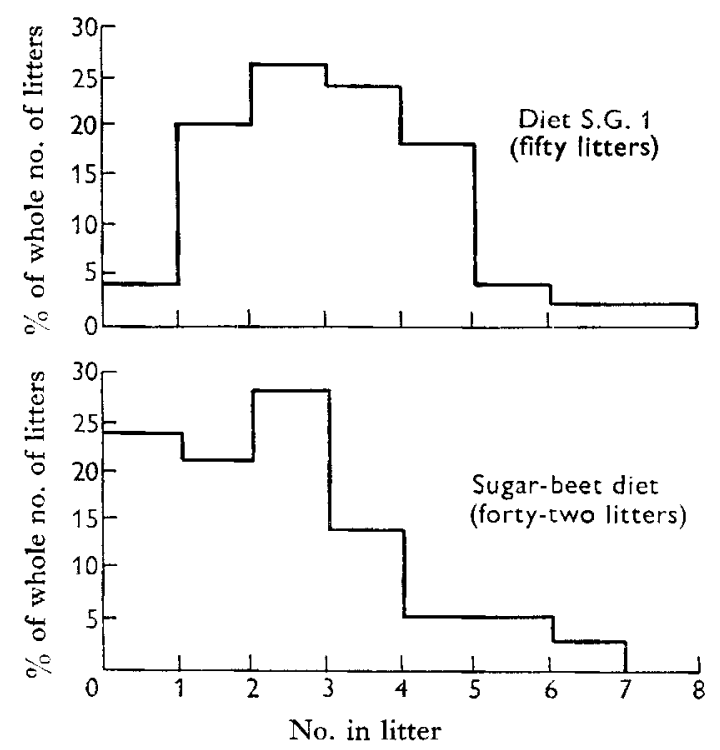

Fig. I. Effects of two diets on the number of young guinea-pigs born per litter (live and still births).

the sugar-beet diet. On diet S.G. I the mean numbers in second, third, fourth and fifth litters were greater than in the first, but this was accompanied by an increase in the total weight of the litters, so that the mean weights of individual young remained about the same. On the sugar-beet diet the number of young in the litters fell after the first one, and the mean weight of the individual young tended to rise. In litter one, therefore, the young were smaller than on diet S.G. I but equal in number; in the subsequent litters fewer young were born, but their weights were about the same.

Fig. I shows the effect of the two diets on the number of young per litter. The information is based upon values for fifty litters and $\mathrm{r} 8 \mathrm{r}$ young born to mothers on diet S.G. I and forty-two litters and II 7 young born to mothers on the sugar-beet diet. On diet S.G. $x$ there were two litters of one and two of seven or eight, whereas on the sugar-beet diet there were ten litters of one and none of eight. The whole trend on this diet was indeed towards smaller litters, and the results are in agreement with those already given in other contexts.

Table 4 gives the effects of the two diets on the numbers born and their weights, on the numbers weaned and on the percentage of those born that died in the first 4 weeks of life. Figures are given for three ranges of birth weight, as well as for the total 
numbers on all three. Only I9\% of the offspring of mothers living on diet S.G. I were in the low birth-weight category and $4 \mathrm{I} \%$ were in the high category, whereas $42 \%$ of the young born to mothers on the sugar-beet mixture were in the low birthweight grouping and only $26 \%$ in the high.

Table 4. Effect of two diets on survival and neonatal mortality of guinea-pigs in the first four litters born

No. born

$\%$ of total no. born on each diet

No. weaned

$\%$ of total no. weaned on each diet
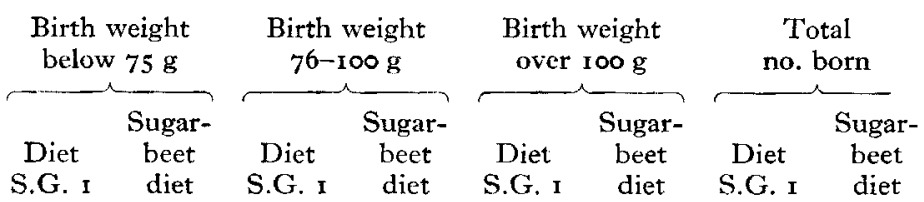

Deaths as $\%$ of births

$\begin{array}{rr}28 & 33 \\ 19 & 43 \\ & \\ 10 & 10 \\ 9 & 27\end{array}$

$57 \quad 24$

$40 \quad 3$ I

59

$4 \mathrm{I}$

$49 \quad 14$

43

$3^{8}$

54

54
48

20

I $44 \quad 77$

$64 \quad 70$

$14 \quad 42$

8

13

113

37

35

-

-

52

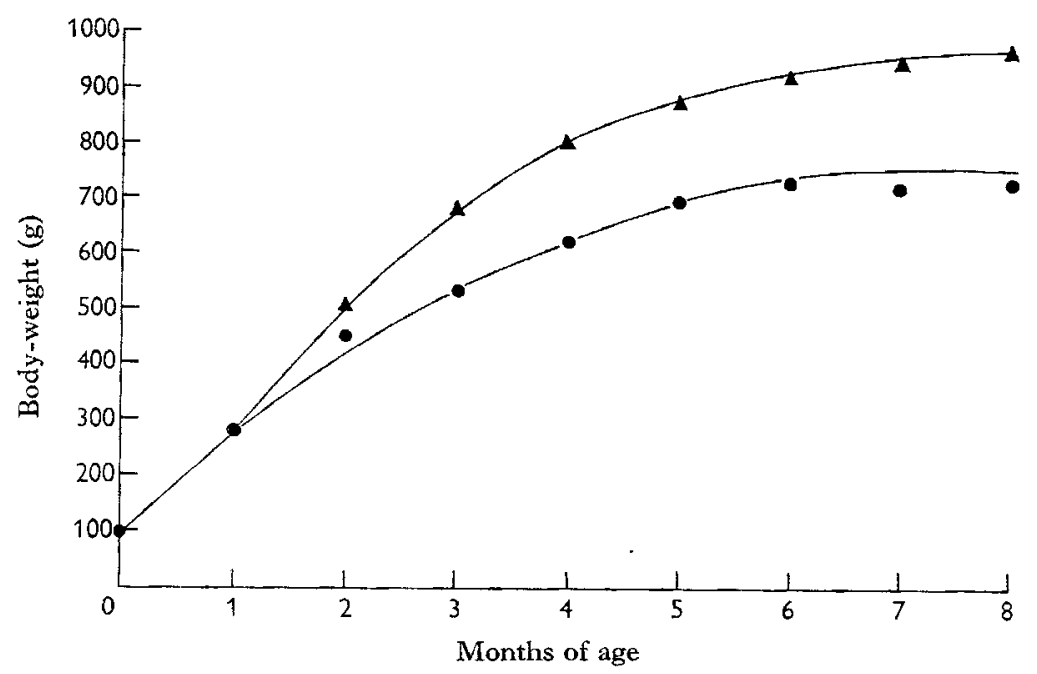

Fig. 2. Mean growth curves of guinea-pigs on two diets. A, diet S.G. I; , sugar-beet diet.

Young guinea-pigs are able to take solid food shortly after birth, and guinea-pig mothers are known to suckle the young of other mothers. The mothers on the sugarbeet diet may not have produced so much milk, but there were fewer young to support because of the high mortality in the neonatal period. The percentage increment in weight from birth to weaning was greatest in the low birth-weight group, not so great in the medium and least in the high group. There appeared to be a small difference between the mean gain in weight from birth to weaning on the two diets, but it was not statistically significant. An examination of the significance of the regressions of weaning weight on birth weight gave a variance ratio of 0.97 for diet S.G. I and of $I \cdot 0$ I 
for the sugar-beet diet. Neither was significant, and it was, therefore, possible to examine the effect of birth weight on final size without having to make allowances for the effect of treatment up to weaning.

Fig. 2 shows the increase in weight from birth to maturity of the population of male guinea-pigs reared from weaning on one or other of the diets. Some of the young in each group (see p. $3^{12}$ ) came from mothers living on the sugar-beet diet, and some from mothers having diet S.G. I and they themselves had had access to the same diet as their mothers until they were weaned. All the animals, therefore, are represented in

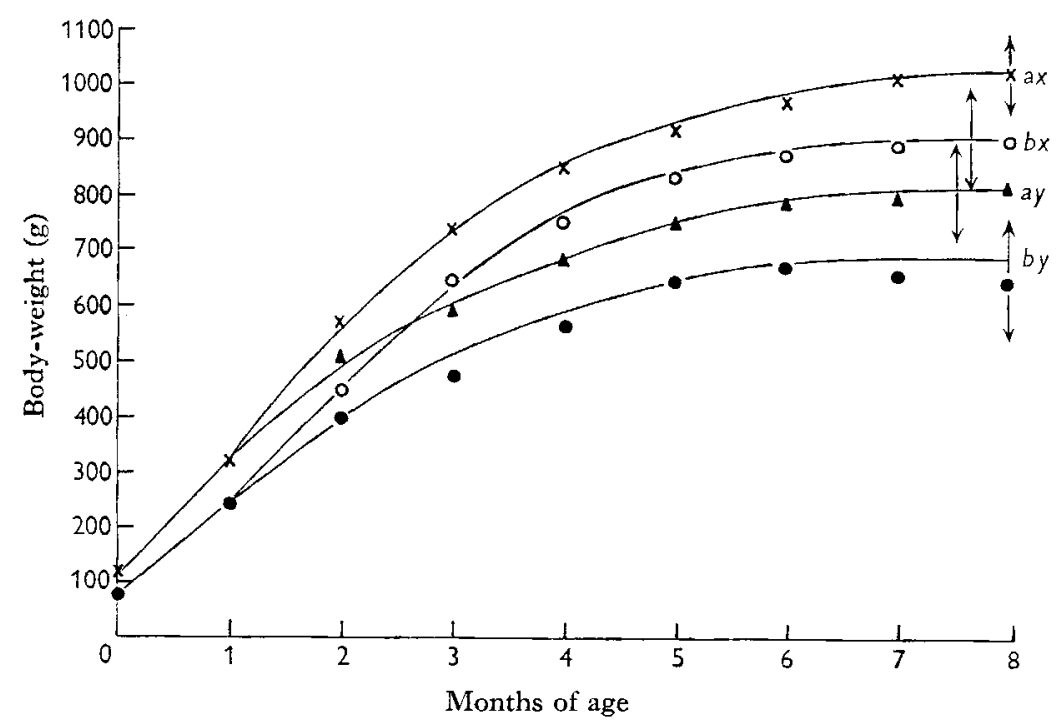

Fig. 3. The growth curves of guinea-pigs reared on two diets. $\times(a x)$, mean birth weight I $13 \mathrm{~g}$, reared on diet S.G. I; $\mathrm{O}(b x)$, mean birth weight $81 \mathrm{~g}$, reared on diet S.G. I ; $\Delta(a y)$, mean birth weight $113 \mathrm{~g}$, reared on sugar-beet diet; $(b y)$, mean birth weight $8 \mathrm{I} \mathrm{g}$, reared on sugar-beet diet.

the single part of the curve from birth to weaning. The mean increase in weight after weaning was more rapid on diet S.G. $x$, and the final weight was significantly greater. Both populations ceased to grow-i.e. to gain weight-at about the same chronological age. When the performances of the individual animals were investigated, it was found that there was a highly significant correlation between birth weight and mature weight on each diet. The coefficients of correlation were 0.764 for diet S.G. I and 0.679 for the sugar-beet diet, both significant at the $\mathrm{I} \%$ level. In other words, there was a strong probability that, given no change of environment, the large animal at birth would be a large animal at maturity.

Fig. 3 shows the average body-weights of the male animals with birth weights over Ioo $\mathrm{g}$ reared from weaning on diet S.G. I (curve $a x$ ) and of those with birth weights below $100 \mathrm{~g}$ reared on the sugar-beet mixture (curve $b y$ ). If the weight at birth be accepted largely as a matter of prenatal nutrition (see above), these curves show essentially the effects of the two diets from conception to maturity. The differences were statistically significant. Again it is to be noted that both groups ceased to gain 
weight at about the same chronological age. Fig. 3 also shows the mean body-weights of the animals with birth weights below $100 \mathrm{~g}$ reared on diet S.G. I after weaning (curve $b x$ ) and of animals with birth weights over $100 \mathrm{~g}$ reared on the sugar-beet mixture (curve ay). The advantage of a high and the disadvantage of a low weaning weight were eliminated before maturity by the nature of the diet after weaning, for both curves $b x$ and $a y$ fell between curves $a x$ and $b y$, showing that the full effects of the two diets from conception to maturity were avoided. Indeed, the group with the higher weight at weaning appeared to have the lower final weight, but the difference was not statistically significant. There can be little doubt, however, that the nature of the diet after weaning had a pronounced biological effect.

Table 5. Effect of weight at birth and nutrition after weaning on the weights and dimensions of adult guinea-pigs

(Five animals in each group)

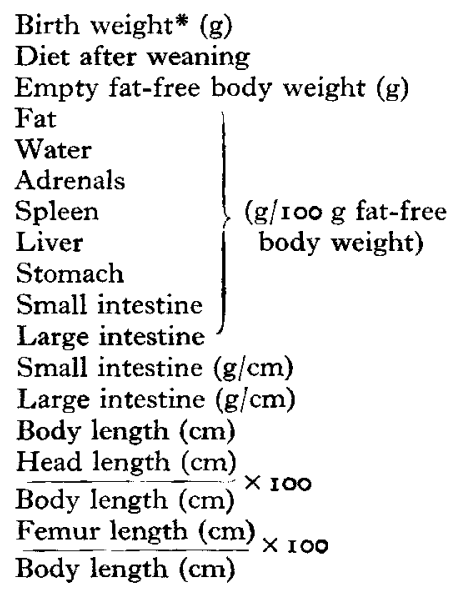

Birth weight* $(\mathrm{g})$

Diet after weaning

Adrenals

Spleen

Stomach

Small intestine

Small intestine $(\mathrm{g} / \mathrm{cm})$

Large intestine $(\mathrm{g} / \mathrm{cm})$

Body length $(\mathrm{cm})$

Head length $(\mathrm{cm})$

Femur length $(\mathrm{cm})$

Body length (cm)
Empty fat-free body weight (g)

$\begin{array}{cc}7 \mathrm{x} \pm 3 \cdot 5 & 75 \pm 4 \cdot 0 \\ \text { Sugar-beet } & \text { S.G.I } \\ 420 \pm 60 \cdot 2 & 653 \pm 126 \cdot 3 \\ 8 \cdot 1 & 10 \cdot 0 \\ 71 \cdot 5 & 71 \cdot 5 \\ 0 \cdot 17 & 0.09 \\ 0.15 & 0.17 \\ 5 \cdot 45 & 4 \cdot 40 \\ 0.98 & 0.89 \\ 3.29 & 2 \cdot 05 \\ 4 \cdot 10 & 2 \cdot 51 \\ 0.09 & 0.08 \\ 0.17 & 0.14 \\ 25 \cdot 2 \pm 1 \cdot 36 & 28 \cdot 9 \pm 1 \cdot 10 \\ 27.4 & 24.9 \\ 17.5 & 15.9\end{array}$

* Value with standard deviation.

$\begin{array}{cc}\text { I24 I } 3.6 & 118 \pm 9.6 \\ \text { Sugar-beet } & \text { S.G. I } \\ 640 \pm 94.2 & 788 \pm 38.7 \\ 10.2 & 16.6 \\ 71.0 & 70.0 \\ 0.12 & 0.10 \\ 0.14 & 0.17 \\ 5.35 & 4.80 \\ 0.94 & 0.76 \\ 2.43 & 1.95 \\ 2.98 & 2.14 \\ 0.09 & 0.09 \\ 0.19 & 0.13 \\ 28.2 \pm 0.04 & 30.7 \pm 0.07 \\ 25.2 & 24.6 \\ 16.4 & 15.6\end{array}$

Table 5 shows the effect of the two diets after weaning on the weight and composition of the bodies of male guinea-pigs 8 months of age that had had birth weights $(a)$ around $73 \mathrm{~g}$, and $(b)$ around $120 \mathrm{~g}$. Information is given about the empty fat-free body weight at death and the water and fat in the carcasses, expressed as percentages of the fat-free body weight, the weights of several organs on the same basis, the weight of the intestines per unit of their length, the length of the body and various somatic measurements expressed as a percentage of this length. Each figure is the mean of measurements made on five animals. As shown graphically in Fig. 3, a low birth weight and the sugar-beet diet after weaning produced the lightest adults and a high birth weight and diet S.G. I the heaviest adults, whereas the effects of birth weight and nutrition up to weaning could be nullified by reversing the plane of nutrition after weaning. The figures for fat tell a similar story. The animals reared on the sugarbeet diet tended to have heavier adrenals and lighter spleens than those on diet S.G. I, both suggesting that they were relatively undernourished. They also had heavier livers, but this in itself does not suggest undernutrition. The nature of the diets made 
no difference to the weights of the testes, heart, kidneys and pancreas, expressed as percentages of the fat-free body weight, and the weights of these organs have not, therefore, been included in Table 5. The small and large intestines of the animals reared on sugar-beet were heavier per unit of fat-free body weight and rather heavier per $\mathrm{cm}$ of length, and both these findings may be attributed to functional hypertrophy (Fell, Smith \& Campbell, I963), here brought about by the bulky nature of this diet. The head and the femur were long in relation to body length in the animals reared on the sugar-beet diet, both results to be expected in undernourished animals while still growing. Few adults have hitherto been investigated.

\section{DISCUSSION}

A comparison of the two diets as set out in Table 2 might have indicated that diet S.G. I was likely to be the better one for some purposes, and the reproductive performance of the guinea-pigs showed that this was so. The mothers on the sugar-beet mixture produced fewer litters and a smaller weight of young per litter than those on diet S.G. I, and considerably more of their young, particularly of the smaller young, died before they were weaned. Curiously, perhaps, the difference in diet made no significant difference to the weight gained by the young between birth and weaning, and during this time on both diets the smaller young made a greater gain/100 $\mathrm{g}$ bodyweight at birth than the larger young. This observation might have been made by Widdowson \& McCance (I955) in their study of the physiological undernutrition of guinea-pigs of this age had not their experimental arrangement precluded it. It is perhaps worth mentioning that their animals came from a colony reared on the sugarbeet diet.

By making an assumption, for which there is considerable evidence (McCance, 1962), that the size of the individual at birth in a pure-bred strain of animals is largely a matter of nutrition in utero whatever the nature of the maternal diet, it was possible to compare the effects of the two diets on growth from weaning to maturity in three ways: first (Fig. 2) when the weaning weights were equal, secondly, when a high plane of nutrition in utero gave place to life on the sugar-beet mixture and when a low plane of nutrition in utero gave place to life on diet S.G. I (Fig. 3), and thirdly, when diet S.G. I and the sugar-beet mixture were consumed after high and low planes of nutrition in utero respectively (Fig. 3). The first comparison gave results again suggesting the inferiority of the sugar-beet mixture, and the two diets produced significant differences between the compositions of the carcasses after death (Table 5). The second comparison showed that the differences created by these two planes of nutrition from conception to weaning could be more than eliminated by reversing them afterwards, and the third comparison demonstrated that highly significant differences could be produced between animals on the high and low planes of nutrition if they were maintained from conception to maturity: in other words it showed that the effects of superior and inferior nutrition before birth and after weaning were cumulative (Fig. 3 and Table 5).

So much for the direct results of these experiments on guinea-pigs. Instructive as they may in themselves be for those who may wish to rear guinea-pigs, their value 
may be enhanced by the inferences that can be drawn from them about the effects of nutrition on the welfare of other species and particularly man. If, for example, a mixture of the two populations, in proportions to be defined, be regarded as the analogue of a human population consisting of rich and poor or of wise and foolish, the experiments show how the spread of the weight of the human population at birth and maturity might be brought about. Further, they offer an opportunity of reproducing experimentally within a reasonable length of time some of the absorbing observations on human growth and stature that can never be put to direct test on man. It should be possible, for instance, to reproduce fairly easily the secular trends in children's heights and weights by altering progressively the diets of successive generations of guinea-pigs and to modify the experiments in any way desired-by introducing or excluding infections, for example. Finding the right animals for experiment is often the only way to understand and even, perhaps, to solve a physiological problem (Bernard, I865).

\section{SUMMARY}

I. Guinea-pigs were bred and reared on two laboratory diets, one based on a sugarbeet-pulp mixture and the other on Short \& Gammage's (1959) S.G. I purchased commercially.

2. The mothers on the sugar-beet diet bred less frequently and had smaller young or smaller litters than those on S.G. I.

3. There was a strong correlation between birth weight and adult weight on both diets.

4. The animals born and bred on the sugar-beet diet became significantly smaller adults than those on diet S.G. I.

5. If the diets of the young were reversed after weaning, the effect of the environment up to weaning could be nullified, and the weights of the adults fell between the weights of those reared on the two diets throughout.

We thank Dr D. A. T. Southgate for analysing the two diets and Miss P. Pledger for her original observation that led to the investigation described and her assistance towards the care of the animals.

\section{REFERENCES}

Bernard, M. C. (1865). Introduction à 'Étude de la Médecine Expérimentale. Paris: J. B. Baillière et Fils. Dalton, D. C. (1965). Nature, Lond., 205, 807.

Fell, B. F., Smith, K. A. \& Campbell, R. M. (1963). F. Path. Bact. 85, 179.

Holst, A. \& Frölich, T. (1907). J. Hyg., Camb., 7, 634 .

Lavoisier, A. L. \& La Place (1784). Histoire de l'Académie Royale des Sciences (avec les Mémoires de Mathématique et de Physique), p. 355. Paris: L'Imprimerie Royale.

McCance, R. A. (1962). Lancet, ii, 621.

McCance, R. A. \& Walsham, C. M. (1948-9). Brit. F. Nutr. 2, 26.

McKeown, T. (1960). Human Growth. London: Pergamon Press.

Meyer, J. H. (1958). Amer. F. Physiol. 193, 488.

Rowlands, I. W. (1949). F. Hyg., Camb., 47, 28I.

Seguin \& Lavoisier, A. L. (1793). Histoire de l'Académie Royale des Sciences (avec les Mémoires de Mathématique et de Physique), p. 566. Paris: L'Imprimerie Royale.

Short, D. J. \& Gammage, L. (1959). F. Anim. Tech. Ass. 9, 62.

Widdowson, E. M. \& McCance, R. A. (1955). Brit. F. Nutr. 9, 316. 